REVIEWS OF INFECTIOUS DISEASES - VOL. 8, SUPPLEMENT 5 - NOVEMBER-DECEMBER 1986

(C) 1986 by The University of Chicago. All rights reserved. $0162-0886 / 86 / 0806-0029 \$ 02.00$

\title{
Single-Dose Pharmacokinetics of Intravenous Sulbactam in Pediatric Patients
}

\author{
Urs B. Schaad, Kathrin Guenin, and \\ Peter Straehl
}

From the Division of Pediatric Infectious Diseases, Department of Pediatrics; and the Department of Medicine, University of Berne, Berne, Switzerland

\begin{abstract}
The pharmacokinetics of intravenously administered sulbactam were studied in 17 pediatric patients two to 14 years of age. Single doses of 12.5 or $25 \mathrm{mg} / \mathrm{kg}$ were infused over $3 \mathrm{~min}$, and in previously healthy children, mean peak plasma concentrations 5 min after dosing were 71 and $163 \mu \mathrm{g} / \mathrm{ml}$, respectively. Noncompartmental and compartmental calculations resulted in similar pharmacokinetic parameters. Linear pharmacokinetics were found in the concentration range studied. The mean terminal-phase half-life was $1.75 \mathrm{hr}$, the mean total plasma clearance was $180 \mathrm{ml} / \mathrm{min}$ per $1.73 \mathrm{~m}^{2}$, and the mean apparent volume of distribution was $340 \mathrm{ml} / \mathrm{kg}$. Approximately $70 \%-80 \%$ of an intravenous dose was excreted unchanged in the urine. In children with cystic fibrosis, both total plasma clearance and apparent volume of distribution were significantly increased. The data support the intravenous administration of $12.5-25 \mathrm{mg}$ of sulbactam $/ \mathrm{kg}$ every 6 to $8 \mathrm{hr}$ for assessing the adequacy of this drug as an adjunct to $\beta$-lactam therapy for various bacterial infections in children.
\end{abstract}

An increasing number of gram-positive and gramnegative organisms that cause infections in children have become resistant to penicillin or cephalosporin compounds through the production of $\beta$-lactamases, enzymes that destroy these antibiotics. One way of restoring the susceptibility of resistant strains of bacteria to these agents is by co-administering an inhibitor of $\beta$-lactamases. Sulbactam is a potent and relatively stable $\beta$-lactamase inhibitor that shows promise as an adjunct to $\beta$-lactam therapy.

The majority of the bacterial agents that cause respiratory tract infections (e.g., pneumonia, bronchitis, sinusitis, otitis), cellulitis, skeletal infections (e.g. arthritis, osteomyelitis), urinary tract infections, and meningitis in children are susceptible to sulbactam plus ampicillin. This group of pathogens includes the $\beta$-lactamase-producing strains of Haemophilus influenzae, Staphylococcus aureus, and Escherichia coli $[1,2]$.

In the present study we evaluated the pharmaco-

Informed consent for these studies was obtained from the parents of the study patients. The guidelines of the local Institutional Committee on Human Investigations were followed in the conduct of this research.

This work was supported in part by a grant from Pfizer Switzerland, Zurich.

We dedicate this paper to our chairman, Prof. Dr. Ettore Rossi, for his 70th birthday.

We thank Dr. J. Krucko for technical assistance and B. Herrmann for secretarial assistance.

Please address requests for reprints to Dr. Urs B. Schaad, Department of Pediatrics, University of Berne, Inselspital, $\mathrm{CH}$ 3010 Berne, Switzerland. kinetics of sulbactam in children. Such pharmacokinetic information should permit the formulation of dosage recommendations for therapeutic trials of this $\beta$-lactamase inhibitor as an adjunct to a $\beta$-lactam compound for pediatric infections.

\section{Patients and Methods}

Study patients. The pharmacokinetics of a single iv dose of sulbactam was studied in 17 children hospitalized at the Department of Pediatrics, University of Berne, for various bacterial infections (eight for bronchopneumonia, five for meningitis, two for lymphadenitis, one for arthritis, and one for epiglottitis). At the time of the study, both specific and nonspecific signs and symptoms of the actual infectious disease had to have markedly improved. The pediatric patients (PP) were divided into three groups according to the dose of sulbactam (PP-1, $25 \mathrm{mg} / \mathrm{kg}$; and PP-2, $12.5 \mathrm{mg} / \mathrm{kg}$ ) or underlying disease (PP$\mathrm{CF}$, pediatric patients with cystic fibrosis treated for bronchopulmonary exacerbations). Characteristics of the groups of patients are listed in table 1. The study participants included 11 boys and six girls. They had no history of allergy to $\beta$-lactam compounds or of renal or hepatic diseases. The hydration and circulation status of each patient was judged to be clinically normal. The study protocol conformed with the guidelines of the Institutional Committee on Human Investigations, Department of Pediatrics, University of Berne; informed parental consent was obtained for all study patients. 


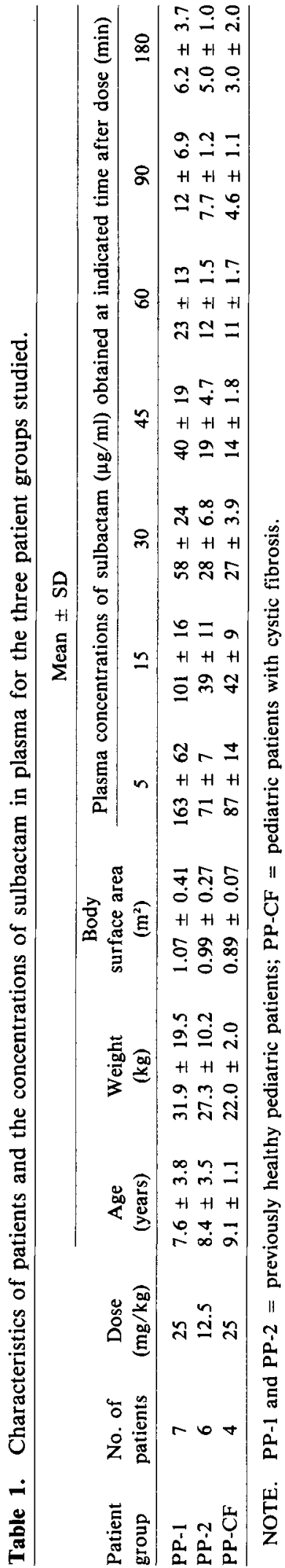

Drug administration. The contents of the drug vials $(500 \mathrm{mg}$ of sulbactam sodium, lot ED-V-219Y81, Pfizer, Sandwich, U.K.) were dissolved in 20 $\mathrm{ml}$ of sterile water immediately before injection; this resulted in a concentration of $25 \mathrm{mg}$ of sulbac$\mathrm{tam} / \mathrm{ml}$. Sulbactam ( 25 or $12.5 \mathrm{mg} / \mathrm{kg}$ ) was infused into a peripheral vein over a 3-min period via an indwelling catheter. The single dose of sulbactam was given in addition to the antimicrobial regimen prescribed for the actual infection.

Collection of biologic specimens. Blood samples for drug assay were collected from an iv heparin lock immediately before the administration of sulbactam (predose sample) and at 5, 15, 30, 45, 60, 90, 180, and $360 \mathrm{~min}$ after the termination of the infusion (the end of the 3-min drug infusion was considered time 0 ). The blood was immediately mixed with sodium citrate and kept at $4^{\circ} \mathrm{C}$ until centrifuged within $2 \mathrm{hr}$. Plasma samples were stored at $-20^{\circ} \mathrm{C}$ until assayed within one week of collection.

The total urine was collected from 12 of the 17 study patients at the following time intervals: $-2-0$ $\mathrm{hr}, 0-2 \mathrm{hr}, 2-4 \mathrm{hr}$, and 4-6 hr after dosing with sulbactam. Urine was sampled either from sterile receptacles (four patients) or by cooperative miction (eight patients). The volumes of voided urine were recorded, and the samples were stored at $-20^{\circ} \mathrm{C}$ until assayed within four weeks of collection.

Sulbactam assay. Plasma and urine samples were analyzed for sulbactam by a specific high-performance liquid chromatographic (HPLC) assay similar to the method previously described by Rogers et al. [3]. The HPLC system consisted of a solvent delivery pump (Altex $100 \mathrm{~A}$, Berkeley, Calif.), a variable wavelength detector (Uvikon 720 LC, Kontron International, Zurich), and a reverse-phase column $(250 \mathrm{~mm} \times 4.6 \mathrm{~mm})$. Injection was performed with a Rheodyne 7120 (Cotatia, Calif.) injection valve fitted with a 20- $\mu$ l sample loop. The mobile phase consisted of $0.05 \mathrm{M}$ ammonium phosphate-methanolphosphoric acid, the flow rate was maintained at 0.7 $\mathrm{ml} / \mathrm{min}$, the ultraviolet detector was set at $210 \mathrm{~nm}$, and the chart speed was $5 \mathrm{~mm} / \mathrm{min}$. Ether extracts of samples were dried under a stream of nitrogen gas at $35^{\circ} \mathrm{C}$. The residue was reconstituted in $75 \mu l$ of the mobile-phase solvent. Calibration curves were prepared by the addition of known amounts of sulbactam to appropriate volumes of blank plasma or urine (spiked). These preparations were treated in the same way as the patient samples. A graph of the area under the peak (obtained with an integrator, 
PLASMA CONCENTRATIONS

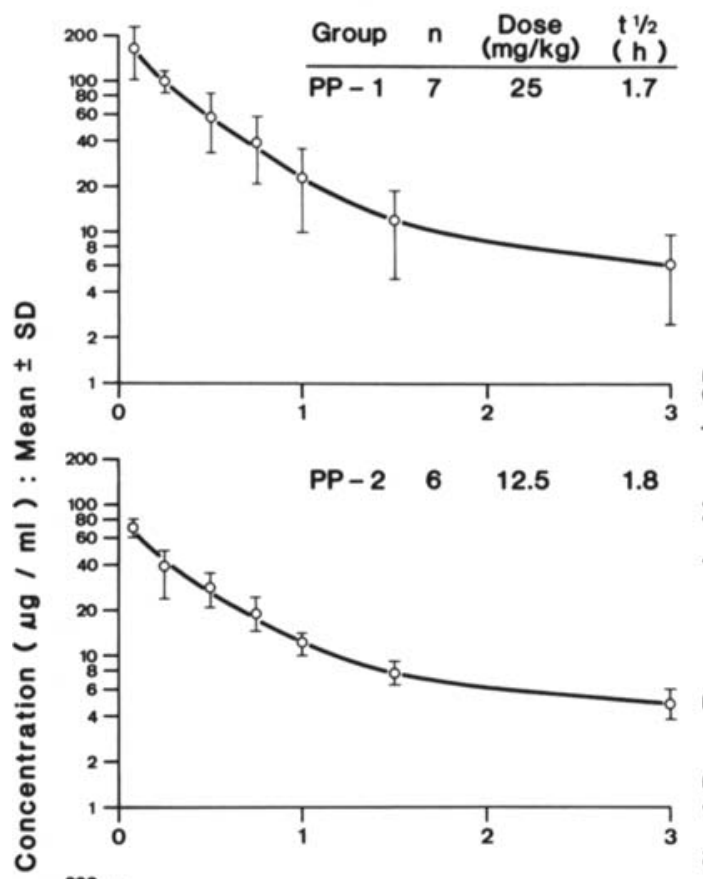

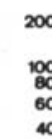

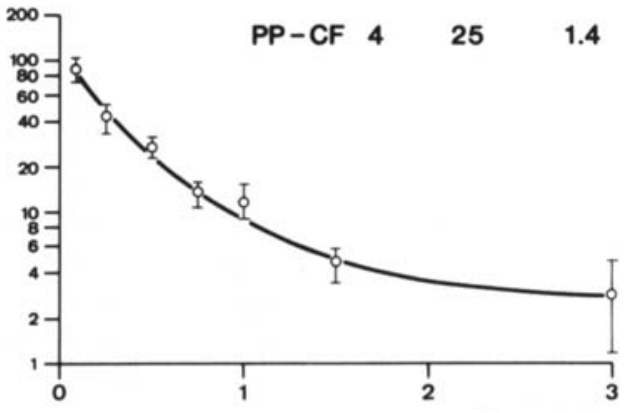

Time After Dose ( hours)

Figure 1. Mean plasma concentration-time curves and mean cumulative percent recoveries of sulbactam in the urine for the three pediatric patient (PP) groups studied. PP-1 and PP-2 were previously healthy; PP-CF had cystic fibrosis. The $t \frac{1}{2}$ is terminal-phase half-life in hours (h). The bars indicate the SD values.

Hewlett-Packard 3380A, Palo Alto, Calif.) against the concentration of sulbactam was constructed for determining concentrations of sulbactam in patient samples. Calibration curves were linear over the concentration range $2-500 \mu \mathrm{g} / \mathrm{ml}$. The lower detection limit was $2 \mu \mathrm{g} / \mathrm{ml}$. Coefficients of variation were $4.2 \%$ for analyses performed on the same day (within-day analysis), and 6.8\% for day-to-day analysis (determined in spiked normal human plasma).

Estimation of pharmacokinetic parameters. Two different methods of analysis (noncompartmental and compartmental) were used for estimating the clinically relevant parameters.

(l) Noncompartmental analysis: The area under the plasma concentration-time curve (AUC) and the area under the moment curve (AUMC) were calculated by fitting a spline function to the individual data and integrating it. Extrapolation to infinity was calculated according to Benet and Galeazzi [4]. The curve used was the cubic natural spline. The terminalphase half-life was calculated by regression on those plasma concentration points visually determined to be in the log linear phase. Compartmental independent plasma clearance $(\mathrm{Cl})$ was determined as originally described by Dost [5]: $\mathrm{Cl}=$ dose/AUC. Volume of distribution at steady state (Vdss) is given: Vdss $=\mathrm{CI} \cdot$ MDRT, where MDRT is the mean disposition residence time, i.e., mean residence time af- 
ter an intravenous bolus. Thus, MDRT = AUMC/AUC and Vdss $=$ dose $\cdot$ AUMC/AUC $^{2}$.

The total renal clearance $\left(\mathrm{Cl}_{\mathrm{r}}\right)$ was derived from the 6 -hr collecting intervals by a semilogarithmic plot of the excretion rate vs. the midpoint of the urine collection period: $\mathrm{Cl}_{\mathrm{r}}=\mathrm{Cl} \cdot \mathrm{Ae}_{\infty} /$ dose, where $\mathrm{Ae}_{\infty}$ is the amount of drug excreted unchanged in urine to infinity.

(2) Compartmental analysis: For compartmental analysis a two-compartment open-body model or a one-compartment open-body model was necessary for an adequate description of the individual plasma concentration-time data after single iv doses of sulbactam. Nonlinear parameter estimation was performed by the method of extended least squares [6] with use of the computer program ELSFIT [7]. In each case, a variance model with variances proportional to some power at the predicted value at the dependent variable was chosen [8].

\section{Results}

Plasma concentrations. Mean plasma concentrations of sulbactam in the three patient groups are listed in table 1 . All of the predose samples were free of sulbactam. Peak plasma concentrations, achieved $5 \mathrm{~min}$ after administration of a $25-\mathrm{mg} / \mathrm{kg}$ dose, ranged from 113 to $286 \mu \mathrm{g} / \mathrm{ml}$ in previously healthy children (PP-1) and from 68 to $103 \mu \mathrm{g} / \mathrm{ml}$ in children with cystic fibrosis (PP-CF); after the administration of the $12.5-\mathrm{mg} / \mathrm{kg}$ doses, peak values ranged from 61 to $79 \mu \mathrm{g} / \mathrm{ml}$ (PP-2). At $180 \mathrm{~min}$ after dosing, measured sulbactam concentrations were 4.7-14.3 $\mu \mathrm{g} / \mathrm{ml}$ in PP-1, 3.6-4.1 $\mu \mathrm{g} / \mathrm{ml}$ in PP-CF, and 3.8-6.2 $\mu \mathrm{g} / \mathrm{ml}$ in PP-2. After $360 \mathrm{~min}$, all the plasma levels either were not detectable (10 patients) or were below the detection limit $(2 \mu \mathrm{g} / \mathrm{ml})$ of the HPLC method used (seven patients). The mean plasma con- centration-time curves of the three patient groups are included in figure 1 . The individual data for plasma concentration vs. time declined either monoor biexponentially and could be described by a oneor a two-compartment open-body model.

The mean pharmacokinetic parameters, calculated by noncompartmental and compartmental methods are listed in table 2. Model-independent (noncompartmental) and model-dependent (compartmental) values of terminal-phase half-life, total plasma clearance, and volume of distribution were in good agreement among the three patient groups. In previously healthy children (PP-1 and PP-2), both doses studied $(25$ and $12.5 \mathrm{mg} / \mathrm{kg})$ produced similar pharmacokinetic values. However, in the cystic fibrosis group (PP-CF), the mean plasma clearance was $\sim 2.2$ times and the mean volume of distribution was $\sim 1.6$ times greater than the values for the other patient groups. These increases led to significantly lower peak plasma levels (table 1) and to slightly shorter terminal half-lives (table 2).

Urine concentrations. Urine samples collected before sulbactam administration contained no detectable drug. The mean values $( \pm S D)$ of the cumulative percentage of the dose recovered in the urine during the three 2-hr intervals from time 0 to $6 \mathrm{hr}$ after dosing are displayed in figure 1. Urine samples were available from 12 of the 17 study patients. By $6 \mathrm{hr}, 73 \%$ (PP-1), $67 \%$ (PP-2), or 81\% (PP-CF) of the initial sulbactam dose was excreted unchanged in the urine. The total amount of sulbactam excreted unchanged in the urine to infinity and the fraction of dose excreted unchanged could be calculated from these data. Mean values $( \pm S D)$ of this fraction were $0.81(0.06)$ for PP-1, $0.73(0.07)$ for PP-2, and 0.91 (0.06) for PP-CF. Therefore, renal clearances accounted for $70 \%-90 \%$ of total plasma clearances.

Safety. Single doses of sulbactam administered

Table 2. Pharmacokinetic parameters of sulbactam calculated by noncompartmental and compartmental methods for the three patient groups studied.

\begin{tabular}{|c|c|c|c|c|c|c|c|}
\hline \multirow[b]{2}{*}{$\begin{array}{l}\text { Patient } \\
\text { group }\end{array}$} & \multirow[b]{2}{*}{$\begin{array}{c}\text { Dose } \\
(\mathrm{mg} / \mathrm{kg})\end{array}$} & \multicolumn{3}{|c|}{ Noncompartmental model } & \multicolumn{3}{|c|}{ Compartmental model } \\
\hline & & $\begin{array}{l}t^{1 / 2} \\
(h r)\end{array}$ & $\begin{array}{c}\mathrm{Cl} \\
(\mathrm{ml} / \mathrm{min} / \\
\left.1.73 \mathrm{~m}^{2}\right)\end{array}$ & $\begin{array}{c}\text { Vdss } \\
(\mathrm{ml} / \mathrm{kg})\end{array}$ & $\begin{array}{l}\mathrm{t} 1 / 2 \\
(\mathrm{hr})\end{array}$ & $\begin{array}{c}\mathrm{Cl} \\
(\mathrm{ml} / \mathrm{min} / \\
\left.1.73 \mathrm{~m}^{2}\right)\end{array}$ & $\begin{array}{c}\text { Vdss } \\
(\mathrm{ml} / \mathrm{kg})\end{array}$ \\
\hline PP-1 & 25 & $1.65 \pm 0.98$ & $187 \pm 62$ & $310 \pm 154$ & $1.74 \pm 0.26$ & $191 \pm 69$ & $312 \pm 245$ \\
\hline PP-2 & 12.5 & $1.77 \pm 0.63$ & $164 \pm 29$ & $385 \pm 83$ & $1.86 \pm 0.21$ & $172 \pm 30$ & $321 \pm 132$ \\
\hline $\mathrm{PP}-\mathrm{CF}$ & 25 & $1.42 \pm 0.83$ & $374 \pm 35$ & $701 \pm 357$ & $1.55 \pm 0.13$ & $445 \pm 70$ & $382 \pm 120$ \\
\hline
\end{tabular}

NOTE. PP-1 and PP-2 = previously healthy pediatric patients; $P P-C F=$ pediatric patients with cystic fibrosis; $t \frac{1}{2}=t$ erminalphase half-life; $\mathrm{Cl}=$ plasma clearance; Vdss = volume of distribution at steady state. 
iv over $3 \mathrm{~min}$ were well tolerated. Although all of the patients were receiving antibiotic drugs other than the study drug, we perceived no local or systemic reactions following the use of sulbactam that we could ascribe to the drug mixtures. Obviously, under the circumstances such data cannot be considered a definitive study of the toxicity of the mixture.

\section{Discussion}

The pharmacokinetics of sulbactam administered iv to children were studied. The pharmacokinetic values for half-life, plasma clearance, and volume of distribution were similar in patients without cystic fibrosis given single doses of 12.5 or $25 \mathrm{mg}$ of sulbactam $/ \mathrm{kg}$. It is therefore concluded that the pharmacokinetics of sulbactam are linear in the concentration range studied.

The individual plasma concentration-time values declined either mono- or biexponentially and, accordingly, could be described by a one- or a twocompartment open-body model. The pharmacokinetic parameters calculated by the compartmental method were in good agreement with the ones calculated by the noncompartmental method. These findings suggest that simple noncompartmental pharmacokinetic analysis is adequate for iv administered sulbactam in pediatric patients.

The ranges of plasma sulbactam concentrations we observed after iv infusion of $12.5-\mathrm{mg} / \mathrm{kg}$ doses are comparable to those reported for adult volunteers after 30-min iv infusion of $1,000 \mathrm{mg}$ of sulbactam [9]. The mean apparent volume of distribution of $340 \mathrm{ml} / \mathrm{kg}$ estimated for previously healthy children also compares favorably with the mean value of $320 \mathrm{ml} / \mathrm{kg}$ for adult volunteers. However, the mean total plasma clearance rate of $180 \mathrm{ml} / \mathrm{min}$ per $1.73 \mathrm{~m}^{2}$ in children is substantially lower than the mean value of $\sim 240 \mathrm{ml} / \mathrm{min}$ per $1.73 \mathrm{~m}^{2}$ in adults [9]. As a consequence, the mean terminal-phase halflife of $1.75 \mathrm{hr}$ in children is significantly longer than the mean values of 0.97 and $0.99 \mathrm{hr}$ reported for adult volunteers $[9,10]$.

The principal mode of elimination of sulbactam is excretion of the structurally unchanged drug in the urine. The renal clearance accounts for $\sim 77 \%$ of the total plasma clearance of sulbactam in children; a similar value has been reported for adults $[9,10]$. Thus, patients with renal dysfunction will require adequate dosage adjustments.
Pharmacokinetic studies of many $\beta$-lactam and aminoglycoside antibiotics have demonstrated altered distribution and elimination of the drugs in patients with cystic fibrosis as compared with the normal population [11]. In the case of sulbactam, both the apparent volume of distribution and the total plasma clearance were significantly increased in the patients with cystic fibrosis. Consequently, in these patients the $25-\mathrm{mg} / \mathrm{kg}$ doses produced plasma concentrations that were only approximately onehalf of those measured in previously healthy pediatric patients; the mean terminal half-life was slightly shorter $(1.42 \mathrm{hr}$ vs. $1.65 \mathrm{hr})$ in the cystic fibrosis patient group than in the previously healthy patient group. Patients with cystic fibrosis will probably require increased dosages.

The pharmacokinetic data presented here and the data on the $\beta$-lactamase inhibitory activity of sulbactam in vitro $[1,2]$ indicate that a dosage of $12.5-$ $25 \mathrm{mg} / \mathrm{kg}$ given iv over $3 \mathrm{~min}$ every $6-8 \mathrm{hr}$ should be adequate for the study of sulbactam as an adjunct to iv $\beta$-lactam therapy for various bacterial infections in children. At present, ampicillin appears to be the most attractive parenteral partner for sulbactam in pediatric patients. The recommended dosage for ampicillin is twice the sulbactam dosage. Studies of the co-administration of these compounds in adults have repeatedly shown that the two are compatible and synchronous in their pharmacokinetics $[9,10]$.

By analogy with single-drug therapy with ampicillin, the dosage suggested above will probably have to be increased two- to fourfold for treatment of invasive infections. It must, however, be emphasized that these dosage recommendations are preliminary and are only intended for well-controlled clinical evaluations.

\section{References}

1. Retsema JA, English AR, Girard AE. CP-45,899 in combination with penicillin or ampicillin against penicillinresistant Staphylococcus, Haemophilus influenzae, and Bacteroides. Antimicrob Agents Chemother 1980;17: 615-22

2. Wise R, Andrews JM, Bedford KA. Clavulanic acid and CP45,899: a comparison of their in vitro activity in combination with penicillins. J Antimicrob Chemother 1980; 6:197-206

3. Rogers HJ, Bradbrook ID, Morrison PJ, Spector RG, Cox DA, Lees LJ. Pharmacokinetics and bioavailability of sultamicillin estimated by high performance liquid chromatography. J Antimicrob Chemother 1983;11:435-45 
4. Benet LZ, Galeazzi RL. Noncompartmental determination of the steady-state volume of distribution. J Pharm Sci 1979;68:1071-4

5. Dost FH. Grundlagen der Pharmakokinetik. Stuttgart: Georg Thieme Verlag, 1976

6. Sheiner LB, Beal SL. Evaluation of methods for estimating population pharmacokinetic parameters. I. MichaelisMenton model: routine clinical pharmacokinetic data. J Pharmacokinet Biopharm 1980;8:553-71

7. Sheiner L. ELSFIT: a program for the extended least-squares fit to individual pharmacokinetic data. San Francisco: University of California, 1980

8. Peck CC, Sheiner LB, Nichols AI. The problem of choosing weights in nonlinear regression analysis of pharmacokinetic data. Drug Metab Rev 1984;15:133-48

9. Foulds G, Stankewich JP, Marshall DC, O’Brien MM, Hayes SL, Weidler DJ, McMahon FG. Pharmacokinetics of sulbactam in humans. Antimicrob Agents Chemother 1983;23: 692-9

10. Brown RM, Wise R, Andrews JM, Hancox J. Comparative pharmacokinetics and tissue penetration of sulbactam and ampicillin after concurrent intravenous administration. Antimicrob Agents Chemother 1982;21:565-7

11. Boxerbaum $B$. The art and science of the use of antibiotics in cystic fibrosis. Pediatr Infect Dis 1982;1:381-3 